AJChE 2020, Vol. 20, No. 2, $205-215$

\title{
Compressive Strength and Water Absorption of Pavement Derived from Palm 0il Eco Processed Pozzolan [EPP] Material as Partial Cement Replacement
}

\author{
Nurul Farhanah Mohd Kusaimi \\ Fazlena Hamzah* \\ Junaidah Jai \\ Nurul Asyikin Md Zaki \\ Norliza Ibrahim \\ Biocatalysis and Biobased Material Technology Research Laboratory, Faculty of Chemical \\ Engineering, Universiti Teknologi MARA, Selangor, Malaysia \\ ‘e-mail: fazlena@uitm.edu.my
}

Eco Processed Pozzolan (EPP) is derived from Spent Bleaching Earth (SBE) by the calcination process via heat treatment in the palm oil refining industry. EPP can be used as a partial replacement of cement as it contains a high amount of silica and has pozzolanic properties. Besides its properties, the sustainable production of EPP in the palm oil industry, abundantly available, and cheaper raw material have opened an opportunity to explore it as a cement substitute in pavement industries. This research aimed to study the properties of pozzolanic EPP and discover its potential as a partial substitute of cement in the pavement block's development. The compressive strength and water absorption of the formulated pavement block using EPP were analyzed in this study. Two sets of paving blocks were developed, namely, Set A, EPP was added as a partial replacement of the cement in pavement formulation at 20\%-90\%, while in Set B, integration of EPP and Fly Ash (FA) was used as a partial replacement of the cement. The results indicated that the maximum addition of EPP into pavement formulation was $20 \%$. The increment of EPP as a cement substitute in a formulation of more than $20 \%$ has reduced the compressive strength and increased the water absorption of the pavement. Simultaneously, the addition of FA and EPP in the formulation of hybrid pavement in Set $B$ shows that the addition of FA has improved the compressive strength of the pavement and less water absorption was detected. The pavement's highest compressive strength by addition of FA was $36 \mathrm{MPa}$ at the EPP was added of $15-20 \%$. The study indicated that EPP could be used as a partial substitute of the cement, but addition of FA might require to improve pavement compressive strength.

Keywords: Cement, Eco Processed Pozzolan, Pavement, Strength, Water Absorption 


\section{INTRODUCTION}

Generally, paving blocks are made of cement, aggregates, and sand. Cement is the main component in which a minimum amount of $210 \mathrm{~kg} / \mathrm{m}^{3}$ is used to the manufacture paving blocks (Ganjian et al. 2015). Many raw materials, such as limestone, clay, and sand, are used to produce cement. The process requires a huge amount of heat that is commonly generated from fuel sources such as coal, natural gas, tires, and hazardous waste. Cement is produced abundantly and due to its large amount of $\mathrm{CO}_{2}$ emitted during the process, it is known to be one of the major contributions to cause detrimental effects to the environment (Hamada et al. 2018).

Alternatively, a siliceous and aluminous material known as pozzolan is proposed as a partial substitute for the cement to minimize environmental effects. Pozzolan is a very finely ground pumice or fly ash, that chemically reacts with calcium hydroxide in the presence of moisture to form silicate or aluminate compounds with cementitious properties (Rathi and Modera 2007). There are two types of pozzolans, which are natural pozzolan and humanmade pozzolan. Natural pozzolans are based on natural minerals and volcanic deposits, while human-made pozzolans are by-products such as silica fume, blast furnace slag, and fly ash from industries. Fly Ash (FA) is the most known and widely used substitution of cement. Up to this day, the worldwide production of fly ash is around 900-1000 million tonnes. FA has been proven to have numerous advantages when acting as a substitute of cement in concrete due to its pozzolanic properties; the advantages include improved workability, reduced permeability and increased compressive strength (Groud and Soni 2016).

Spent Bleaching Earth (SBE) is produced as solid waste in the palm oil industry and is usually disposed off to landfills (Wangrakdiskul et al. 2015). Further extraction and refining of SBE before undergoing calcination via heat treatment produces calcined compounds called EcoProcessed Pozzolan (EPP). EPP as cement replacement in the making of paving blocks can reduce dependency on the cement in the manufacturing industry. It will eventually reduce $\mathrm{CO}_{2}$ emission and fossil fuel consumption. The durability of the paving block using EPP can also reduce the amount of repair work required. It is because EPP will create a dense cement paste, limiting the penetration of chloride ions and reducing the corrosion of steel reinforcements. Moreover, it will provide a good surface finish and reduce pores of paving blocks.

Furthermore, EPP allows higher yield in the concrete mix, and, therefore a lesser amount of EPP is needed than other cement replacements. The pozzolanic properties and high silica content in EPP convey the best recommendation for precast concrete and building material products. The pozzolanic reaction converts a silica-rich material to a calcium silicate with good cementing properties. The reaction occurs when calcium hydroxide $\left(\mathrm{Ca}(\mathrm{OH})_{2}\right)$ reacts with the silica and produces calcium silica hydrate (C-S-H) paste, which acts as a binding glue to 
increase the strength of any cement-based materials. The $\mathrm{C}-\mathrm{S}-\mathrm{H}$ paste will also help to reduce pores and improve the strength and durability of paving blocks. However, research on EPP has not been well explored and reported despite its valuable benefits as a cement substitute.

Thus, the present work focuses on the effects of partially substituting cement with EPP in paving block formulation. The pavement was evaluated based on its compressive strength and the ability to withstand the absorption of water. In this work, different EPP and FA ratios were used to determine the optimum EPP formulation for the paving block. This work's outcomes can be beneficial for the construction industries in formulating cement substitute, thus reducing the material cost with enhanced durability while minimizing environmental pollution.

\section{MATERIALS AND METHODS}

\section{Materials}

Materials used in the making of the paving block were of commercial grade. Ordinary Portland Cement (OPC), fine sand, and coarse aggregates were purchased from ATKC Hardware Trading (Malaysia). The Eco Processed Pozzolan (EPP) was obtained from Palm Oil Refining Industries in Selangor, Malaysia. Fly Ash (FA) was provided by YTL Buildcon Concrete (Malaysia). The water to cement ratio used for this research was 0.38 .

\section{Pavement Development}

Two sets of experiments were conducted, Set A and Set B. For Set A, EPP was used as a partial cement replacement at $0 \%$,
$20 \%, 40 \%, 60 \%, 80 \%$ and $90 \%$ by weight of cement. Set B (hybrid), 20\% of cement substitute was used, and FA was added to the mixture with EPP as a partial cement replacement. The percentage of EPP to FA was $0 \%, 5 \%, 10 \%, 15 \%, 20 \%$ and $25 \%$. The mixing of the materials was conducted according to the proportions tabulated in Table 1 and Table 2. After mixing, each formulation set was placed separately in a $100 \mathrm{~mm} \times 100 \mathrm{~mm} \times 100 \mathrm{~mm}$ paving block mould and left to dry at room temperature. The dried paving block was then soaked in water for the curing process for 7 days before further analysis.

Table 1. Experimental set up with EPP (Set A)

\begin{tabular}{ccccc}
\hline \multirow{2}{*}{$\begin{array}{c}\text { Cement Sand } \\
\text { (g) }\end{array}$} & (g) & \multirow{2}{*}{$\begin{array}{c}\text { Coarse } \\
\text { Aggregate }\end{array}$} & \multicolumn{2}{c}{ EPP } \\
\cline { 4 - 5 } & & $(\mathbf{g})$ & $\%$ & Mass (g) \\
\hline 528 & 633 & 792 & $0 \%-90 \%$ & $0-475.2$ \\
\hline
\end{tabular}

Table 2. Experimental set up with integration of EPP and FA (Set B)

\begin{tabular}{ccccc}
\hline \multirow{2}{*}{$\begin{array}{c}\text { Cement Sand } \\
(\mathbf{g})\end{array}$} & $\mathbf{( g )}$ & $\begin{array}{c}\text { Coarse } \\
\text { Aggregate }\end{array}$ & \multicolumn{2}{c}{ Pozzolanic (20\%) } \\
\cline { 4 - 5 } & & $\mathbf{( g )}$ & EPP (\%) & FA (\%) \\
\hline 528 & 633 & 792 & $0-25$ & $100-75$ \\
\hline
\end{tabular}

\section{Compressive Strength Test}

The compressive strength test was conducted on the developed pavement using a compressive strength test machine (OEM/KINGENTER, model YES-2000BS) to determine the maximum compressive load that the paving block can bear before fracturing. Compressive strength was calculated using Eq. (1). 
208 Compressive Strength and Water Absorption of Pavement Derived from Palm Oil Eco Processed Pozzolan (EPP) Material as Partial Cement Replacement

Compressive Strength $=$

$$
=\frac{\text { Applied Load }(\mathrm{N})}{\text { Plan Area }\left(\mathrm{mm}^{2}\right)}
$$

\section{Water Absorption Analysis}

The water absorption test was conducted to measure the amount of water absorbed into the pavement pore structure. This test was conducted by soaking the paving blocks in water for 7 days. The paving block's weight before and after it emerged in water was taken, and the water absorption was calculated using Eq. (2).

Water Absorption $=\frac{W_{S}-W_{D}}{W_{S}} \times 100 \%$

Where:

$W_{S}=$ Weight of concrete after curing for 7 days $(\mathrm{g})$

$W_{D}=$ Weight of concrete before curing $(g)$

\section{RESULTS AND DISCUSSION}

\section{Physical and Chemical Analysis of EPP}

Table 3 shows the physical and chemical properties of EPP. The EPP physical appearance is spherical, with an average density between $1.80-1.90 \mathrm{MT} / \mathrm{m}^{3}$. The composition analysis indicates that EPP consists of high silica content, around 44 $47 \%$. The chemical composition of EPP makes it significant as the cement replacement. Ordinary Portland Cement (OPC) has reported that silica composition after fabrication is approximately about $25 \%$ silica-containing material (The constructor 2020), which is lower compared to EPP. The mean particle size, $d_{50}$ of EPP and OPC, was 29.3 and $27.4 \mu \mathrm{m}$, respectively. Meanwhile, the particle size, $d_{90}$ of EPP and OPC was 80.42 and 94.36 $\mu \mathrm{m}$, respectively (Abd Rahman et al. 2020).

Table 3. Physical and Chemical Properties of EPP

\begin{tabular}{cc}
\hline \multicolumn{2}{c}{ Physical Properties of EPP } \\
\hline Particle Shape & Spherical \\
Density, MT/m ${ }^{3}$ & $1.80-1.90$ \\
\hline \multicolumn{2}{c}{ Chemical Properties of EPP } \\
\hline Sulphate Content, \% & $1.0-1.5$ \\
Moisture, \% & 0.5 \\
Reactive Silica, \% & $44-47$ \\
\hline
\end{tabular}

\section{Compressive Strength of Paving Blocks at Different Percentage of EPP}

Two sets of experiments were conducted, Set A and Set B. Set A was carried out by replacing cement with EPP at $0 \%, 20 \%, 40 \%, 60 \%, 80 \%$, and $90 \%$. For Set $\mathrm{B}$, the hybrid pavement was carried out by adding FA and EPP at $0 \%, 5 \%, 10 \%, 15 \%$, $20 \%$, and $25 \%$ with the constant mass of cement. The produced paving block was shown in Figure 1.

As can be observed from the developed pavement block, different formulation and percentage of EPP resulted in different color and structure of the pavement. It might be due to the hydration reaction that occurs during the mixing of cement, EPP, and water. The strength of the paving blocks with different percentages of EPP as a partial cement replacement is shown in Figure 2.

Figure 2 shows that a higher percentage of EPP in the paving blocks results in lower compressive strength of the block. It was found that paving block with 0\% EPP represents the highest strength 
with a value of $45.3 \mathrm{MPa}$. When the EPP was added into the mixture from $20 \%$ to $90 \%$, the pavement strength decrement was recorded. The pavement's highest compressive strength with the addition of EPP was observed at $20 \%$, which gave the pavement strength at $32.4 \mathrm{MPa}$, and the paving block with $90 \%$ EPP gave the lowest compressive strength with the value of 2.3 $\mathrm{MPa}$.

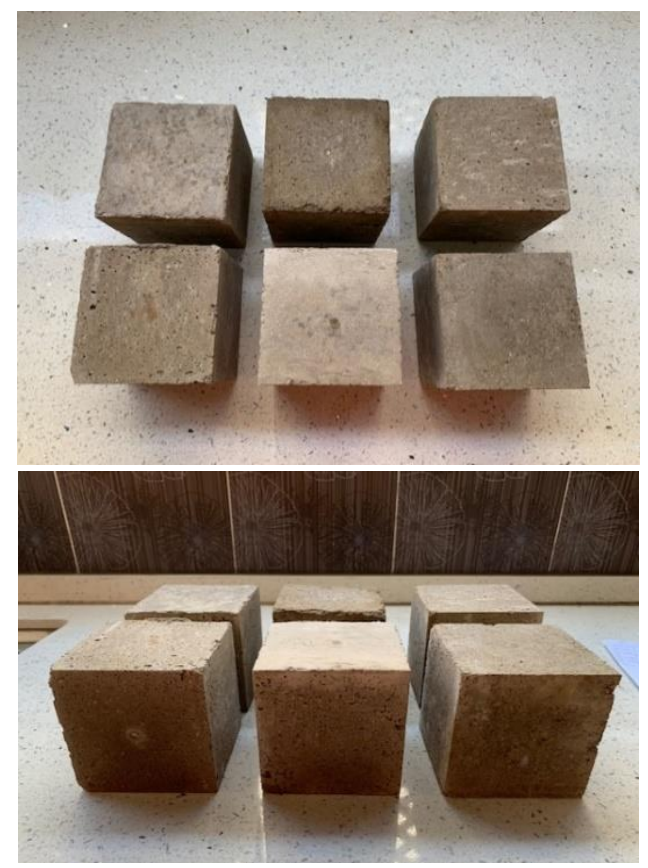

Fig. 1: Pavement Block Developed using EPP

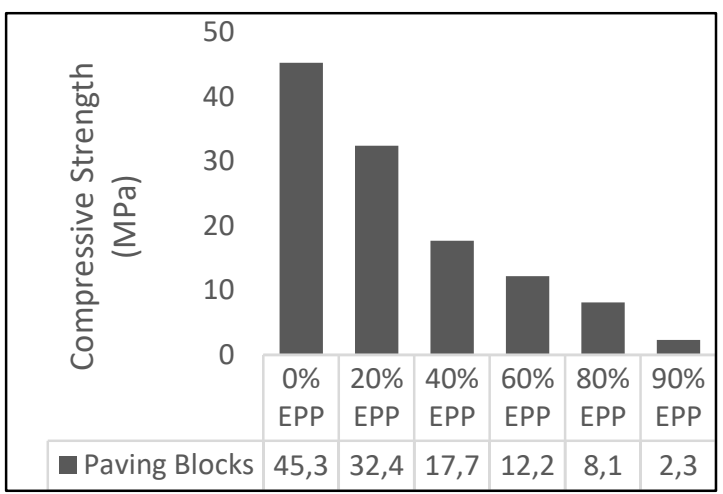

Fig. 2: Compressive Strength of Paving Blocks at Different Percentage of EPP
The highest compressive strength obtained from the pavement block without EPP indicated the role of tricalcium silicate $\left(\mathrm{Ca}_{3} \mathrm{SiO}_{5}\right)$ composition in OPC cement, which strengthen the pavement block. In the formulation of cement, $50 \%$ of the cement composition comes from tricalcium silicate that provided the strength to the pavement. Another $25 \%$ is from dicalcium silicate $\left(\mathrm{Ca}_{2} \mathrm{SiO}_{4}\right)$ that also contributes to the strength of the pavement. With the reduction of the cement, the amount of tricalcium silicate might be reduced and significantly affected the pavement's strength.

The composition of reactive silica $\left(\mathrm{SiO}_{2}\right)$ in the EPP as obtained by chemical analysis was $44-47 \%$ (Table 3 ). With this capacity, reactive silica needs to react with available calcium hydroxide to form cementitious hydration products with binding properties (Antiohos and Tsimas 2005) as illustrated in Eq. 3.

$$
\mathrm{Ca}(\mathrm{OH})_{2}+\mathrm{SiO}_{2} \rightarrow \mathrm{CaSiO}_{3} \cdot \mathrm{H}_{2} \mathrm{O}
$$

Based on this reaction, the mixture's hydration reaction with EPP depends on the amount of calcium hydroxide that is released during the reaction of tricalcium silicate $\left(\mathrm{Ca}_{3} \mathrm{SiO}_{5}\right)$ with water. This mechanism elaborates the reduction of the pavement strength with the addition of higher EPP. A similar result has been reported by Olonade et al. (2017), which indicated that paving blocks without the addition of pozzolanic materials gave the highest compressive strength. OPC cement works well in providing pavement with good compressive strength. 
This work suggested that 20\% EPP is the maximum suitable for cement substitute in this pavement formulation. By considering the minimum standard of the compressive strength for pavement is at $30 \mathrm{MPa}$ (Velumani and Senthilkumar 2018), paving block with 20\% EPP is considered acceptable for application with the designed compressive strength at 32.4 MPa. As for the paving blocks from $40 \%$ EPP to $90 \%$ EPP, the compressive strength was decreased and is considered weak for the application of paving block. Compressive strength below $30 \mathrm{MPa}$ is not fit to be used because it can easily fracture when a small load is applied to it.

\section{Compressive Strength of Hybrid Paving Blocks Derive from EPP and Fly Ash (FA)}

FA was integrated into EPP in the paving block formulation to increase the compressive strength of the pavement. The effect of integration of EPP and FA on the pavement's compressive strength is illustrated in Figure 3. The results reveal that the paving block's control formulation (0\% EPP, 100\% FA) gave the highest compressive strength, which is $39.63 \mathrm{MPa}$. The strength was reduced to $23.02 \mathrm{MPa}$ when the mixture contained 5\% EPP and 95\% FA. According to Akhbar et al. (2016), reactive silica present in the $\mathrm{FA}$ is $28.87 \%$. With the low amount of reactive silica in FA compared to EPP, less formation of $\mathrm{CaSiO}_{3} \cdot \mathrm{H}_{2} \mathrm{O}$ will occur in the reaction of $\mathrm{SiO}_{4}$ with $\mathrm{Ca}(\mathrm{OH})_{2}$, so the compressive strength of the pavement was reduced.

However, as the percentage of EPP increases $(10 \%, 15 \%$, and $20 \%$ of EPP in the mixture), the strength of paving blocks also increases to $30.48 \mathrm{MPa}, 36.13 \mathrm{MPa}$, and
$36.21 \mathrm{MPa}$, respectively. Hybrid paving block with the addition of 15 and $20 \%$ integrated EPP and FA have the highest compressive strength, which is around $36 \mathrm{MPa}$.

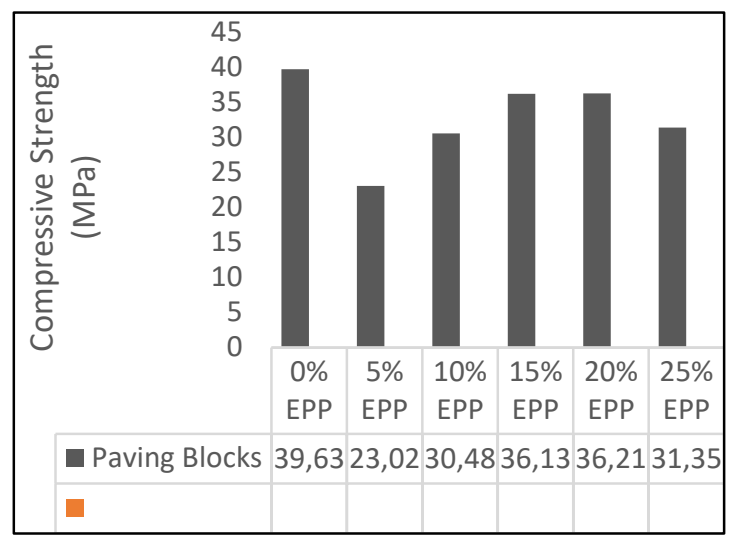

Fig. 3: Compressive strength of hybrid paving blocks at different percentage of $E P P+F A$

The comparison of compressive strength between pavement with and without FA was tabulated in Table 4. The present results are consistent with Goud and Soni's (2016) work in which the addition of $10-20 \%$ FA as partial replacement of cement provides blocks with higher compressive strength. Meanwhile, Wankhede and Fulari (2014) reported on the effects of fly ash on the properties of concrete and concluded that concrete with $10 \%$ and $20 \%$ FA as partial replacement of cement shows good compressive strength for 28 days than normal concrete. However, when 30\% FA was added to the formulation, the concrete's ultimate compressive strength was decreased. This finding suggested that the addition of not more than $20 \%$ of FA into the formulation of EPP paving blocks can increase the compressive strength of the pavement. 
Table 4. Comparison of compressive strength in Set $A$ and $B$

\begin{tabular}{lc}
\hline \multicolumn{1}{c}{$\begin{array}{c}\text { Pavement } \\
\text { formulation }\end{array}$} & $\begin{array}{c}\text { Compressive } \\
\text { strength (MPa) }\end{array}$ \\
\hline $\begin{array}{l}\text { Pavement with } \\
\text { 20\% EPP } \\
\text { Pavement with } \\
\text { 20\% FA } \\
\text { Pavement with } \\
15 \text { \& 20\% EPP }+ \\
\text { 85 \& 80\% FA }\end{array}$ \\
\hline
\end{tabular}

Another finding by Devu and Sreerath (2019) on the effect of FA in glass pavement also indicated the significance of FA in the formulation to increase the pavement's strength. The findings show that glass pavement without FA gave the pavement strength of $54.4 \mathrm{MPa}$, but with the addition of $5 \% \mathrm{FA}-15 \%$ glass powder, the strength of the pavement became $56.07 \mathrm{MPa}$. The pavement gains its strength due to the reaction of calcium hydroxide, a cement crystallization product that reacts with the available fly ash in the mixture to form calcium aluminium silicate, which tends to harden the mixture and thereby shows improved strength (Islam et al. 2020). Moreover, FA can fill the voids between soil particles because of the glass bead structure of FA. It tends to make the soil-FA mix uniform, promoting the hydration reaction of cement ( $\mathrm{Gu}$ and Chen 2020). The hydrated Calcium Aluminate Hydrate (C-A-H) and Calcium Silicate Hydrate (C-S$\mathrm{H}$ ) imparts strength to the matrix. These hydrated products remain wrapped by the soil particles and the bonding capacity of the soil-cement matrix is significantly improved which tends to increase the strength of the blocks prepared with FA addition (Duan and Zhang 2020).

\section{Water Absorption of the Pavement Blocks}

The purpose of the water absorption test is to determine the paving block's moisture content as a percentage of its dry weight. According to Fujiura (1988), the average water absorption of concrete shall not be greater than $8 \%$. Figure 4 shows the percentage of water absorption for the developed paving blocks A with EPP as a partial replacement of cement. The lowest percentage of water absorption for Set $A$ was $3.18 \%$ in the block without EPP.

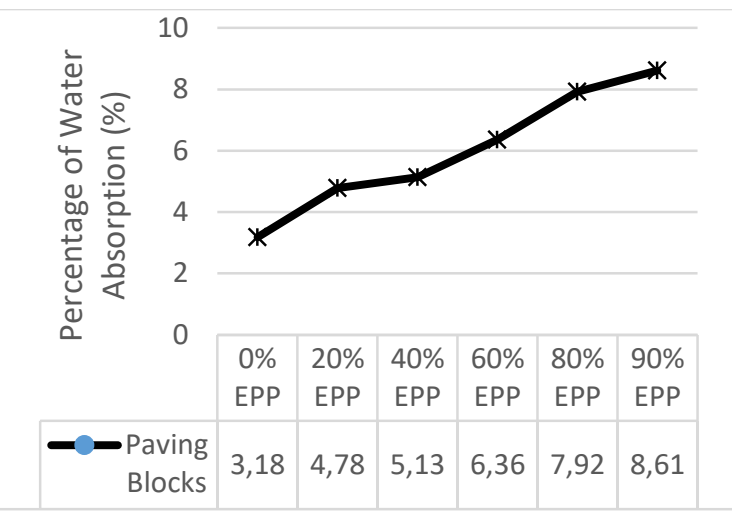

Fig. 4: Percentage of water absorption for paving blocks Set A

The percentage of water absorption increases as the number of EPP increases in the mixture. In Set $A$, the percentage of water absorption was $4.78 \%$ for a paving block with 20\% EPP and significantly increased with EPP increment in paving blocks. At 40\%, 60\%, $80 \%$ and $90 \%$ EPP, the water absorption was $5.13 \%, 6.36 \%, 7.92 \%$ and $8.61 \%$, respectively. The finding indicates that with a higher EPP percentage in the pavement, more water was absorbed. It might be due to its larger capillaries that are formed during the hydration reaction process. Different composition and constituent materials added into the 

Processed Pozzolan (EPP) Material as Partial Cement Replacement

mixture will contribute to the different morphology of the pavement after the reaction. Thus, the molecules of water can fill the void and small empty spaces between the mixture.

Permeability and water absorption of concrete blocks were affected by the pore structure of cement paste and liquid transfers from the surface into the interior (Zhang and Zhong 2014). Concrete permeability has a close relationship with the characteristics of its pore structure in the cement paste and the intensity of microcracks at the aggregate-cement paste interface and within the paste itself (Schutter and Audenaert 2004). Theoretically, pore structure mainly involves with volume and size of the interconnected capillary pores. During hydration reaction, solid and pores systems will be created and forming a pore network that allow the transport of fluid into the concrete. The capillary pressure and effective porosity can significantly change the performance of sorption. Capillary pressure is related to the pore size through the Young-Laplace equation, and effective porosity refers to the pore space in the capillary and gel pores. In addition, different pore size leads to different capillary pressure. This network's development depends on several factors such as the properties and composition of concrete constituent materials, curing condition and duration, age of testing, climate exposure, and conditioning of concrete (Ramli and Tabassi 2004, Shafiq and Cabrera 2014).

Similar results were shown in Figure 5 for hybrid pavement block Set $B$, where the percentage of water absorption increases as more EPP is used in the mixture. In hybrid pavement, FA is known for its pozzolanic properties and very fine particle size (Jiang et al. 2018). FA is spherical particles with less than $1 \mu \mathrm{m}$ diameter, and the average diameter is about $0.15 \mu \mathrm{m}$, which has classified it as an ultrafine material (Pathak 2020).

It can fill the voids between other particles causing less water to be absorbed in the paving blocks. With 5\% EPP, the water absorption was $2.45 \%$ and increased by $0.21 \%$ in paving block with $10 \%$ EPP. The percentage of water absorption increased to $2.7 \%, 2.77 \%$, and $3.55 \%$ at paving blocks with $15 \%$, 20\%, and $25 \%$ EPP, respectively.

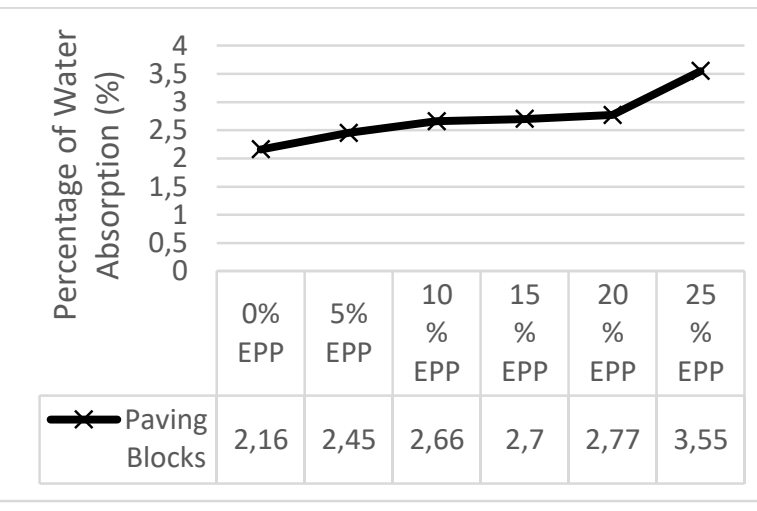

Fig. 5: Percentage of water absorption for paving blocks Set B

Table 5 shows a comparison between the percentage of water absorption for paving blocks Set $A$ and Set B. When comparing water absorption at 20\% EPP, Set $A$ resulted in $4.78 \%$ of water absorption while Set B resulted in $2.77 \%$ water absorption. It indicated that higher content of FA in the formulation could avoid absorption of water in the paving blocks. As reported previously by Aparna et al. (2018), water absorption mainly depends on the matrix's pore distribution. This mechanism 
depends on the composition of the FA added to the mixture. Fly ash, as it is a finer size particle, fills the pores simultaneously densifies the mortar mixes, in which eliminates sorption of water into the block.

Table 5. Comparison of water absorption in Set $A$ and $B$

\begin{tabular}{ccc}
\hline $\begin{array}{c}\text { Percentage of Water } \\
\text { Absorption }\end{array}$ & Set A & Set B \\
\hline Paving Block 20\% EPP & $4.78 \%$ & $2.77 \%$ \\
\hline
\end{tabular}

\section{CONCLUSIONS}

The present study indicated that pozzolanic materials have siliceous and aluminous properties, which are suitable for partial cement replacement. However, the composition of EPP higher than $20 \%$ has reduced the compressive strength and increased the pavement's water absorption. The findings show that $20 \%$ of EPP in the pavement provided the compressive strength of up to $32.4 \mathrm{MPa}$ and as low as $4.78 \%$ of water absorption. The strength of the pavement was improved in the hybrid formulation of the pavement by integrating of EPP with FA. A percentage of $15-20 \%$ composition of EPP integrated with FA provided the compressive strength of the pavement up to $36 \mathrm{MPa}$ and water absorption as low as $2.8 \%$. These key findings summarize the capabilities of EPP to be used as a partial substitute to cement, but with the addition of FA in the formulation to increase the compressive strength of the pavement.

\section{ACKNOWLEDGEMENT}

The present study was made possible through funding from Research Management Institute (RMI) under research grant 600-IRMI/DANA 5/3/BESTARI (129/2018), and continuous support from Ministry of Sciences, Technology and Innovation (MOSTI); Faculty of Chemical Engineering, Universiti Teknologi MARA (UiTM) and Institute of Graduate Studies UiTM are gratefully acknowledged.

\section{REFERENCES}

1. Ganjian, E., Jalull, G., and SadeghiPouya, H. (2015). "Reducing cement contents of paving blocks by using mineral waste and by-product materials", J. Mater. Civ. Eng., 27(1), 112.

2. Hamada, H.M., Jokhio, G.A., Yahaya, F.M., and Humada, A.M., Gul, Y. (2018). "The present state of the use of palm oil fuel ash (POFA) in concrete", Constr. Build. Mater., 175, 26-40.

3. Rathi, V. R. and Modhera, C. D. (2007). "An overview on the Influence of Nano Materials on Properties of Concrete", International Journal of Innovative Research in Science, Engineering and Technology (An ISO Certified Organization), 3297(2), 17-24.

4. Goud, V. and Soni, N. (2016). "Partial Replacement of Cement with Fly Ash in Concrete and Its Effect", IOSR Journal of Engineering (IOSRJEN), 06(10), 2-69.

5. Wangrakdiskul, U., Khonkaew, P., and Wongchareonsin, T. (2015). "Use of the 
214 Compressive Strength and Water Absorption of Pavement Derived from Palm Oil Eco Processed Pozzolan (EPP) Material as Partial Cement Replacement

Spent Bleaching Earth from Palm Oil Industry in Non-Fired Wall Tiles", The International Journal of Advanced Culture Technology, 3(2), 15-24.

6. The contructor - Civil Engineering Home. Retrieved at https://theconstructor.org/concrete/or dinary-portland-cement/23181/ November 2020)

7. Abd Rahman, R.F., Asrah, H., Rizalman, A.N., Mirasa, A.K., and Rajak, M.A.A. (2020). "Study of Eco-Processed Pozzolan Characterization as Partial Replacement of Cement", J. Environ. Treat. Tech., 8(3), 967-970.

8. Antiohos, S.K. and Tsimas, S. (2005). "Investigating the role of reactive silica in the hydration mechanisms of highcalcium fly ash/cement systems", Cem. Concr. Compos., 27, 171-181.

9. Olonade, K. A., Jaji, M. B., and Adekitan, O. A. (2017). "Experimental comparison of selected pozzolanic materials", African Journal of Science, Technology, Innovation and Development, 9(4), 381-385.

10. Velumani, P. and Senthilkumar, S. (2018). "Production of sludgeincorporated paver blocks for efficient waste management", J. Air Waste Manage. Assoc., 68(6), 626-636.

11. Akbar, H., Krishan, G., Prajapati, S.D., and Saini, R. (2016). "Determination of Reactive Silica (SiO2) of Fly Ash", Rasayan J. Chem., 9, 27 - 30.

12. Wankhede, P.R., and Fulari V.A. (2014). "Effect of Fly ASH on Properties of Concrete", International Journal of Emerging Technology and Advanced Engineering, 4, 284 - 289.

13. Devu, K. and Sreerath, S. (2019).
"Experimental Investigation on Partial Replacement of Cement with Fly Ash and Glass Powder", In National Conference on Structural Engineering and Construction Management, Proceedings of SECON'19, 73-82.

14. Islam, M.S., Elahi, T.E., Shahriar, A.R., and Mumtaz, N. (2020). "Effectiveness of fly ash and cement for compressed stabilized earth block construction", Constr. Build. Mater., 255, 119392.

15. Gu, K. and Chen, B. (2020). "Loess stabilization using cement, waste phosphogypsum, fly ash and quicklime for self-compacting rammed earth construction", Constr. Build. Mater., 231, 117195.

16. Duan, X.L. and Zhang, J.S. (2019). "Mechanical properties, failure mode, and microstructure of soil-cement modified with fly ash and polypropylene fiber", Adv. Mater. Sci. Eng., 9561794, 113.

17. Fujiura, Y. (1988). "Water Absorption", en'i Gakkaishi, 44(9), 350-351.

18. Zhang, S.P. and Zong, L. (2014). "Evaluation of Relationship between Water Absorption and Durability of Concrete Materials" Adv. Mater. Sci. and Eng., 650373, 1-8.

19. Schutter, G.D. and Audenaert, K. (2004). "Evaluation of water absorption of concrete as a measure for resistance against carbonation and chloride migration," Materials and Structures, 37, 591-596.

20. Ramli, M. and Tabassi, A.A. (2012). "Effects of polymer modification on the permeability of cement mortars under different curing conditions: a correlational study that includes pore distributions, water absorption and 
compressive strength," Constr. Build.

Mater., 28(1), 561-570.

21. Shafiq, N. and Cabrera, J. G. (2004). "Effects of initial curing condition on the fluid transport properties in OPC and fly ash blended cement concrete," Cem. Concr. Compos., 26(4), 381-387.

22. Jiang, C., Guo, W., Chen, H., Zhu, Y., Jin, C. (2018). "Effect of filler type and content on mechanical properties and microstructure of sand concrete made with superfine waste sand", Constr. Build. Mater., 192, 442-449.

23. Pathak, A. (2020). "Effect of Silica Fume and Fly Ash as Partial Replacement of Cement on Strength of Concrete", International Conference of Advance Research and Innovation (ICARI-2020), 167-170.

24. Aparna, S., Sathyan, D., and Anand, K.B. (2018). "Microstructural and rate of water absorption study on fly-ash incorporated cement mortar", Materials Today: Proceedings, 5, 23692-23701. 